Please do not remove this page

RMIT

UNIVERSITY

\title{
Preparation and rheological characteristics of ethylene-vinyl acetate copolymer/organoclay nanocomposites
}

Lee, Hyung; Park, Bong; Choi, Hyoung; Gupta, Rahul; Bhattacharya, Satinath

https://researchrepository.rmit.edu.au/esploro/outputs/9921860631101341/filesAndLinks?institution=61RMIT_INST\&index=null

Lee, H., Park, B., Choi, H., Gupta, R., \& Bhattacharya, S. (2007). Preparation and rheological characteristics of ethylene-vinyl acetate copolymer/organoclay nanocomposites. Journal Of Macromolecular Science Part B-Physics, 46, 261-273. https://doi.org/10.1080/00222340601066956

Document Version: Accepted Manuscript

Published Version: https://doi.org/10.1080/00222340601066956

Repository homepage: https://researchrepository.rmit.edu.au

Copyright (c) Taylor \& Francis Group, LLC

Downloaded On 2023/04/27 00:35:07 +1000

Please do not remove this page 


\section{Preparation and Rheological Characteristics of Ethylene-Vinyl Acetate}

\section{Copolymer / Organoclay Nanocomposites}

Hyung Min Lee ${ }^{a}$, Bong Jun Park ${ }^{a}$, Rahul Kumar Gupta ${ }^{b}$, Sati N. Bhattachary ${ }^{b}$ and Hyoung Jin Choi ${ }^{\mathrm{a} *}$

${ }^{a}$ Department of Polymer Science and Engineering, Inha University, Incheon 402-751, Korea

${ }^{\mathrm{b}}$ Rheology and Materials Processing Centre, School of Civil and Chemical Engineering, RMIT University, Melbourne, Victoria 3000, Australia

E-mail: $\underline{\text { hjchoi@inha.ac.kr }}$

Keywords: ethylene-vinyl acetate copolymer, organoclay, nanocomposite, rheology

\section{Citation:}

Lee, H, Park, B, Choi, H, Gupta, R and Bhattacharya, S 2007, 'Preparation and rheological characteristics of ethylene-vinyl acetate copolymer/organoclay nanocomposites', Journal Of Macromolecular Science Part B-Physics, vol. 46, pp. 261-273. 


\section{Abstract}

Ethylene-vinyl acetate copolymer (EVA) with $40 \mathrm{wt} \%$ vinyl acetate content (EVA40)/ organoclay nanocomposites were prepared via a melt intercalation method with several different clay concentrations $(2.5,5.0,7.5$, and $10.0 \mathrm{wt} \%)$. X-ray diffraction confirmed the formation of exfoliated nanocomposite in all cases with disappearance of the characteristic peak corresponding to the $d$-spacing of the pristine organoclay. Transmission electron microscopy studies also revealed an exfoliated morphology of the nanocomposites. Morphology and thermal properties of the nanocomposites were further examined by means of scanning electron microscopy (SEM) and thermo gravimetric analysis (TGA), respectively. Rheological properties of the EVA40/organoclay nanocomposites were investigated using a rotational rheometer with parallel-plate geometry in both steady shear and dynamic modes, demonstrating remarkable differences with the clay contents in comparison to that of pure EVA40 copolymer. 


\section{INTRODUCTION}

Polymer/clay nanocomposties are a new emerging class of organic-inorganic hybrid materials. With nanoscopic dispersion of a tiny amount of inorganic clay (montmorillonite, saponite, kaolinite, etc.) with platelet-like structures in a polymeric matrix $[1,2]$, they often exhibit remarkable improvement of material properties when compared with those for pure polymer or conventional polymer composites (micro- or macro-composites) with such fillers as glass fiber and carbon fiber. These improvements include enhanced physical and mechanical properties of high tensile moduli and strength $[3,4]$, increased dimensional stability $[5,6]$, decreased gas permeability and flammability [7], improved solvent and UV resistance [8], improved electrical property and increased biodegradability of biodegradable polymers [9]. The main reason for these enhanced properties in the nanocomposites is caused by the very high aspect ratios $(10-1000)$ and/or large surface area of exfoliated clay particles and the strong interfacial interaction between the silicate platelets of $1 \mathrm{~nm}$ layer thickness and the polymer matrix [1-9]. Furthermore, the clay is naturally abundant, cheap, and environmentally friendly.

On the basis of the strength of the polymer /clay interactions, intercalated, exfoliated, and tactoid nanocomposite systems are generally known. Among these, the intercalated structure is a form where one or more extended polymer chains are inserted into the clay gallery with fixed interlayer spacing, while the exfoliated structure is 
obtained when the silicate clay layers are completely dispersed in a polymer matrix. To achieve full exfoliation of clay in a polymer matrix, the clay particles must be premodified with an organic ammonium cationic surfactant. Among various polymeric materials for polymer/clay nanocomposites, ethylene vinyl acetate copolymer (EVA), a random copolymer consisting of ethylene and vinyl acetate (VA) as a repeating unit, has been recently adopted for its nanocomposite system due to its potential engineering application in the fields of packaging films and adhesives [10, 11]. The EVA copolymer is synthesized through the copolymerization of ethylene and vinyl acetate by a high pressure, high temperature, bulk polymerization process just like low density polyethylene; it possesses various properties when changing the initial concentration of vinyl acetate. Especially, the crystallinity of the EVA, controlled by the vinyl acetate contents, affects the properties of the obtained EVA. As the VA content increases, the copolymer presents less crystallinity, more polarity and different physical behaviors [12, 13]. Common grades have vinyl acetate contents ranging from $1 \% \sim 50 \%$ by weight depending upon the application [14]. Recently, several groups have extensively studied EVA copolymer nanocomposites with various vinyl acetate (VA) contents [15-18].

In this paper, we prepared exfoliated EVA/organoclay nanocomposite with rather high (40 wt $\%$ ) VA content compared to those previously reported and characterized their physical and rheological properties [19]. Since the vinyl acetate group is polar, it is well known that increasing the VA content in the EVA increases the polarity of EVA [20] and thus affects characteristics of EVA40/clay nanocomposite. Main emphasis has been put on both steady shear and dynamic rheological properties of exfoliated EVA40/clay nanocomposites with different clay loadings. 


\section{EXPERIMENTAL}

\section{Materials}

Organo-modified montmorillonite (MMT) clay, Cloisite ${ }^{\circledR}$ 30B (C30B) by Southern Clay Products (Gonzales, USA), was used as received. The pristine $\mathrm{Na}^{+}-\mathrm{MMT}$ has been treated with a quaternary ammonium salt of methyl, tallow, bis-2-hydroxyethyl (with a cation exchange capacity (CEC) of $90 \mathrm{meq} / 100 \mathrm{~g}$ clay). EVA copolymer with $40 \mathrm{wt} \%$ of vinyl acetate (EVA40), supplied by Dupont Inc., (Melbourne, Australia) was used without any purification.

\section{Nanocomposite preparation}

All nanocomposites were prepared using the melt blending technique. Prior to feeding the samples into an extruder, both the polymer and the organoclay were dry-mixed for about 1 minute and then fed into an intermeshing counter-rotating twin-screw extruder (Brabender, Duisburg, Germany). Composites with varying filler level (2.5, 5, 7.5 and $10 \% \mathrm{w} / \mathrm{w}$ ) were prepared and the relevant processing conditions are shown in Table 1 below. The nanofiller, C30B for EVA40 was chosen according to the manufacturer's recommendations.

\section{Characterization}

Immediately after the sample preparation, various methods were used for the characterization of the EVA40/organoclay nanocomposites. Change of interlayer distance of the organoclay in the EVA40 matrix was checked via wide angle X-ray diffraction (WAXD); a Rigaku X-ray diffractometer (the wavelength of $0.154 \mathrm{~nm}$ : a rotating anode type $(\mathrm{Cu}-\mathrm{K} \alpha)$ ) with $40 \mathrm{kV}$ accelerating voltage and $40 \mathrm{~mA}$ current for 
recording data within a range of $2 \theta=1.0 \sim 30^{\circ}$. In addition, to examine the X-ray diffraction of the nanocomposites more accurately, especially at a low angle, small angle X-ray scattering (SAXS) experiments were adopted using a rotating anode type $(\mathrm{Cu}-\mathrm{K} \alpha)$ of Rigaku X-ray diffractometer (DMAX-2500) with $40 \mathrm{kV}$ accelerating voltage and $120 \mathrm{~mA}$ current $[21,22]$. Intensities in the range of $2 \theta=0.06 \sim 3^{\circ}$ were recorded. Transmission electron microscopy (TEM) images were obtained with a Phillips CM200 operated at an acceleration voltage of $120 \mathrm{kV}$. The samples were ultramicrotomed using a RMC ultramicrotome with a CR-X Cryosection attachment at $-160^{\circ} \mathrm{C}$. Note that preparing TEM sample by cutting both pristine EVA and nanocomposite samples at room temperature was extremely difficult due to the rubbery nature of the EVA. The morphology of a cross-sectional surface fractured after dipping into a liquid $\mathrm{N}_{2}$ was observed by scanning electron microscopy (SEM) (Hitachi S-4300, Japan) under the condition of $3 \mathrm{~K}$ magnification and $10 \mathrm{KV}$. The thermal properties were examined using a thermogravimetric analyzer (TGA) (Q50 thermogravimetric analyzer, TA Instrument, USA). The measurement was carried out under a nitrogen environment by purging nitrogen gas at $20 \mathrm{ml} / \mathrm{min}$ and heating from room temperature to $600^{\circ} \mathrm{C}$ at a heating rate of $20^{\circ} \mathrm{C} / \mathrm{min}$. Both steady shear and linear viscoelastic properties of the neat EVA40 and its nanocomposites were measured by using a rotational rheometer (Physica MCR300, Germany) with a parallel-plate geometry $(25 \mathrm{~mm}$ diameter). The stress relaxation measurements were also performed for both neat EVA40 and EVA40/clay nanocomposites at a fixed 5\% strain. All the measurements were carried out in the molten state of the samples at $130^{\circ} \mathrm{C}$ with $1 \mathrm{~mm}$ gap distance.

\section{RESULTS AND DISCUSSION}

The nanocomposite structure was characterized using both XRD and TEM, in 
which these analyses were sensitive enough to detect a crystalline structure of the clay in the polymer/clay nanocomposites. Especially, the WAXD and SAXS of the XRD offer a convenient method to determine the interlayer spacing of the clay layers, while the TEM allows a qualitative understanding of the internal structure through direct visualization.

XRD patterns for the pure organoclay (C30B) powder and EVA40/ clay nanocomposites with different clay loadings are presented in Figure 1. The $d$-spacing (001) of the clay interlayer of the nanocomposites was calculated based on the observed peaks by using the Bragg equation: $\lambda=2 \mathrm{~d} \sin \theta \quad(\lambda=0.154 \mathrm{~nm})$. In the scattering curve for the pure clay as shown in Fig. 1(a), the salient peak $\left(\mathrm{d}_{001}\right)$ corresponding to the basal spacing of Cloisite 30B occurs at $1.85 \mathrm{~nm}$. However, this reflection peak disappears in the scattering curves for all the EVA40/clay nanocomposites in the WAXS without showing any corresponding Bragg peaks. On the other hand, the shoulder peaks of all the EVA40/clay nanocomposites at about $2 \theta=6^{\circ}$ can be regarded to be the $\mathrm{d}_{001}$ peak of $\mathrm{C} 30 \mathrm{~B}$ shifted toward a higher angle of almost $2^{\circ}$, because some parts of the $\mathrm{C} 30 \mathrm{~B}$ will shrink due to the detachment of cationic quaternary ammonium surfactant during melt processing at $130^{\circ} \mathrm{C}$. In addition, the lack of order at higher $d$-spacing (under $2 \theta=3^{\circ}$ ) can be confirmed from SAXS data (Figure 1(b)). This SAXS plot did not show any characteristic diffraction peak of the dispersed clay layers, demonstrating successful exfoliated formation of the EVA40/clay nanocomposites.

This observation can also be confirmed by the TEM images for the internal structure of EVA40/clay nanocomposites as shown in Figure 2 for $2.5 \mathrm{wt} \%$ (a), $5.0 \mathrm{wt} \%$ (c), $7.5 \mathrm{wt} \%$ and $10 \mathrm{wt} \%(\mathrm{~d})$. Even though XRD analyses are useful in examining interlayer d-spacing of ordered layered silicate structures, they may fall short when no 
scattered intensity peaks are observed and such lack of peaks could be interpreted as exfoliation. Therefore, TEM has been regarded to be essential as it gives a direct evidence of what structure exists in the nanocomposite [23]. All the EVA40/clay nanocomposites were found to indicate individual dispersion of completely delaminated clay sheets in the EVA40 matrix from the TEM. The clay platelets were dispersed well, possibly due to the high matrix polarity. The increased number of clay platelets can be observed as the clay contents increased. Note that the vinyl acetate (VA) is a polar functional group that is attached to the ethylene backbone, and the higher the VA content, the higher the polarity. Prasad et al. [23] has already reported that besides the ethylene backbone providing a point of contact between the EVA chain and clay layers via the surface modifier, the VA group can help by attaching itself to an unmodified region of the clay layers that is virtually hydrophilic. Therefore, EVAs with higher VA of $40 \mathrm{wt} \%$ will be able to have a greater degree of interaction with layered silicates compared with previously studied ones with 9,18 and $28 \%$ VA contents, thus producing a much greater enhancement of melt properties. The strong interaction between EVA40 and clay might occur to such extent that the pure clay of dense layered structure was shown to be broken apart and dispersed with individual platelets in the matrix polymer. From the study of nanocomposites of EVA with different VA content, Pasanovic-Zujo et al. [10] reported that EVA28 and EVA18 were predominantly exfoliated while EVA9 was mostly intercalated.

Figure 3 shows the morphology of the fractured surface of pure EVA40 and EVA40 / clay nanocomposites observed by SEM. We can examine the morphological changes of EVA40/clay nanocomposite. The SEM micrograph of pure EVA40 (Fig. 3 (a)) does not show any interesting morphological information; however, distinct morphological 
changes with two different domains appear in which the bright portions in the SEM image were thought to be fractured boundary induced due to the influence of clay presence [17]. The structural evolution of the EVA40/clay nanocomposites system with increasing clay content showed rougher surfaces.

The thermogravimetric curves (Figure 4) demonstrated that the incorporation of clay in the EVA affects its thermal stability. Thermal degradation characteristics of EVA40 and EVA40/clay nanocomposites in nitrogen gas surroundings showed two distinct regions. At the first step, the degradation of EVA40/clay nanocomposites became faster than that of the pure EVA. This can be assigned to the loss of acetic acid which was accelerated as a function of clay loading, possibly due to catalytic effect of the acidic sites of the clay [24-26]. Such increase in degradation rate with increasing amount of dispersed clay was observed in the TGA results for synthetic biodegradable aliphatic polyester/clay nanocomposite [27]. Lim et al. [27] explained such findings indicating that the clay acts as a heat barrier. Although it could enhance the overall thermal stability of the system, as well as assisting in the formation of char after thermal decomposition, the heat barrier effect would result in a reverse thermal stability in the first step. Since the clay also acts as a heat reservoir with higher heat conductivity than polymer matrix, local heating at the boundary of the clay layers enhances thermal degradation of the EVA40. The second step of degradation is the main-chain 
degradation. At temperature, beyond about $400^{\circ} \mathrm{C}$ we found that the EVA40/clay nanocomposites have a higher thermal stability. That is, OMMT can enhance the thermal stability of the main chain of EVA. In general, clay possesses an excellent barrier property and prevents against the permeation of gas or liquid, because nanometer-sized silicate platelets are impenetrable to diffusing gas/liquid molecules. The effect on the barrier property of polymer/clay nanocomposites mainly depend on the degree of exfoliation. Furthermore, it has been also reported that the thermal performance of nanocomposites could be enhanced by hindering the volatile products generated during thermal decomposition process [28].

Since the viscoelastic properties of a particle suspension depend on the structure, particle size and shape, the rheology can be used to provide a tool to examine the structural evolution and the dispersion quality of polymer/clay nanocomposites in a melt state. Figure 5 shows the plot of the shear viscosity as a function of the shear rate for the pure EVA40 and EVA40/clay nanocomposites system at $130^{\circ} \mathrm{C}$ in the molten state. The systems displayed shear thinning behavior with increasing clay contents [29-31]. The appearance of shear thinning means the existence of a structure formed by either intercalation or exfoliation between polymer and clay. The higher the clay content, the higher the degree of shear thinning observed. The increase of the degree of shear thinning also means the nanocomposites became more solid-like. Furthermore, the pure EVA40 shows a Newtonian plateau behavior at around 0.02 /s shear rate. In addition to the increase of shear viscosity, increasing clay concentration shifts Newtonian plateau to 
lower shear rates, leading to an earlier onset of shear thinning. Those with clay contents of $7.5 \%$ and $10 \%$ hardly indicated any sign of a Newtonian plateau with a zero shear viscosity possibly due to the presence of a three-dimensional network structure within the shear rate range tested [23]. Such a behavior can be analyzed quantitatively via a Carreau model curve fitting parameter as follows:

$$
\eta=\frac{\eta_{0}-\eta_{\infty}}{\left[1+\left(\gamma t_{1}\right)^{2}\right]^{(1-n) / 2}}+\eta_{\infty}
$$

Where $\eta$ is an apparent shear viscosity, $\eta_{0}$ is a zero shear viscosity, $\eta_{\infty}$ is an infinitive shear viscosity, $t_{1}$ is a relaxation time and $n$ is a power law index. The power law index (n) is just a criterion of the degree of shear thinning. If $n=1$, the fluid flows like a Newtonian fluid. If $\mathrm{n}<1$, the fluid complies with shear thinning are pseudo-plastic behavior. The zero-shear viscosity $\left(\eta_{0}\right)$ can be obtained from the Carreau model. Zeroshear viscosity, power law index and relaxation time are listed in Table 2. The shear viscosities of EVA40/clay nanocomposites are higher than that of pure EVA40 at a low shear rate. The enhancement arises from the interaction and dispersion of the clay in the polymer matrix. Although the shear viscosity of EVA40 at $10 \mathrm{wt} \%$ clay is larger than that of the others, all of these nanocomposites have similar shear viscosity at high shear rates due to the alignment and orientation of clay particles. Prasad et al. [23] also reported that at high shear rates, the shear viscosity of EVA18 nanocomposites was independent of clay loadings. These results are due to polymer chain conformation changes and reorientation of clay particles under shear, leading to preferential orientation and alignment of clay layers and polymer chains in the flow direction. The 
EVA40/clay nanocomposites can be melt-processed due to this shear thinning property, thus manufacturing can be simplified [32]. Furthermore, a yield stress, which is characterized with a shear viscosity slope of -1 in the low shear rate region, is another rheological property we can deduce from this steady shear rheological measurement especially for higher clay contents. The presence of a yield stress implies a network structure which is related to the concentration and strength of a material formed as a result of polymer matrix-clay and clay-clay interactions [23].

The viscoelastic properties measured at $130^{\circ} \mathrm{C}$ for EVA40 and EVA40/clay nanocomposites are plotted as a function of angular frequency in Figure 6. With an oscillatory measurement, the viscoelastic response of materials can be investigated without any destruction of the internal structure of the samples if the experiment is performed within the linear viscoelastic region $[33,34]$. In order to assure this condition, a test was performed to verify the linear correlation between amplitude and material function such as storage or loss modulus prior to the angular frequency sweep measurements. In the case of EVA40, the amplitude deformation was fixed at $1 \%$ in the dynamic measurement. In Figure 6(a) and 6(b), storage ( $\left.G^{\prime}\right)$ and loss $\left(G^{\prime \prime}\right)$ moduli were obtained simultaneously as a function of an applied frequency, showing that both storage and loss moduli increased monotonously with angular frequency. Depending on the material characteristics, the resultant response represents solid-like or liquid-like behavior. The materials behave like a solid for $G^{\prime}>G^{\prime}$, while like a fluid for $G^{\prime}<G^{\prime \prime}$ (see Fig. 6c). With the increase of clay loading, the nanocomposites exhibited more solidlike behavior $[35,36]$. In addition, a shift of the crossover point towards the lower frequency region of G' and G" was observed. However, the crossover points for more than $5 \mathrm{wt} \%$ clay loadings nanocomposites were not seen, even at very low angular 
frequency as presented in Figure 6(c). In other words, the storage modulus $\left(\mathrm{G}^{\prime}\right)$, which is the index of elasticity, can increase remarkably with clay loadings, due to a strong interaction between EVA40 and clay.

Figure 7 shows stress relaxation behaviors of EVA40 and EVA40/clay nanocomposites at a fixed strain of $5 \%$, measured using a rotational rheometer. $G(t)$, in general, describes the time behavior of a material system. In short and medium timescales up to 5 seconds, the relaxation behavior is qualitatively similar for all nanocomposites and pure EVA40. However, for long timescales, neat EVA40 relaxes like a liquid, whereas the nanocomposites with increasing clay contents behave more like solid materials. On the basis of $\mathrm{G}(\mathrm{t})$, it is clear that the addition of clay has a profound effect on the longtime relaxation of the nanocomposites. By increasing the loading of clay, the higher relaxation modulus $G(t)$ is observed for all time ranges, which may be caused by the enhanced elasticity (more solid-like) resulting from the increased clay loading. These changes of stress relaxation behavior of the EVA40/clay systems in the long time region were considered to be due to restricted stress relaxation of the confined polymer chains occupied by the meso-structure generated due to a strong interaction between clay platelets.

\section{Conclusion}

EVA40/organoclay nanocomposites were prepared using a melt blending technique. The change in the clay interlayer spacing as a function of the clay loading was examined; exfoliation of the clay in the polymer matrix was confirmed by X-ray diffraction investigation. TEM images also showed the exfoliated silicate layers. Microstructure and surface morphology of the nanocomposite systems were examined 
by SEM. The pure EVA40 was featureless; however, distinct morphological changes with different two domains in the nanocomposites appear in which the bright portions in the SEM image were thought to be fractured boundary induced due to the influence of clay presence. The structural evolution of the EVA40/organoclay nanocomposite systems with increasing clay content showed rougher fracture surfaces.

The structural change and the effect of interfacial interaction on the extent of exfoliation as well as on the rheological properties of EVA40/clay nanocomposites with the clay contents were further investigated. A dramatic increase in elasticity was found with the addition of clay, which was confirmed by the storage modulus measurements. The solid-like behavior appeared to be due to good dispersion of clay in the EVA40 matrix.

\section{Acknowledgement}

One (H. J. Choi) of the authors acknowledge research grants from the Korean Science and Engineering Foundation. 


\section{REFERENCES}

1. Kojima, Y.; Usuki, A.; Kawasumi, M.; Okada, A.; Fukushima, Y.; Kuruachi, T.; Kamigaito, O. Mechanical-properties of nylon 6-clay hybrid. J. Mater. Res. 1993, 8, 1185-1189.

2. Park, S. J. ; Li, K. ; Hong, S. K. Preparation and characterization of layered silicatemodified ultrahigh-molecular-weight polyethylene nanocomposites. J. Ind. Eng. Chem. 2005, 11, 561-566.

3. Koo, C. M.; Kim, S. K.; Chung, I. J. Study on morphology evolution, orientational behavior, and anisotropic phase formation of highly filled polymer-layered silicate nanocomposites. Macromolecules. 2003, 36, 2748-2757.

4. Widya, T.; Macosko, C. W. Nanoclay-modified rigid polyurethane foam. J. Macromol. Sci.-Phys. 2005, B44, 897-908.

5. Zeng, C.; Lee, L. J. Poly(methyl methacrylate) and polystyrene/clay nanocomposites prepared by in-situ polymerization. Macromolecules. 2001, 34, 4098-4103.

6. Gilman, J. W. Flammability and thermal stability studies of polymer layered-silicate (clay) nanocomposites. Appl. Clay. Sci. 1999, 15, 31-49.

7. Lu, C.; Mai, Y. W. Influence of aspect ratio on barrier properties of polymer-clay nanocomposites. Phys. Rev. Lett. 2005, 95, 088303.

8. Ma, S. L. ; Kim, Y. S. ; Lee, J. H. ; Kim, J. S. ; Kim, I. ; Won, J. C. Synthesis and property of colorless polyimide and its nanocomposite for plastic display substrate. Polymer-Korea 2005, 29, 204-210. 
9. Sinha Ray, S.; Yamada, K.; Okamoto, M.; Ueda, K. New polylactide-layered silicate nanocomposites. 2. Concurrent improvements of material properties, biodegradability and melt rheology. Polymer 2003, 44, 857-866.

10. Pasanovic-Zujo, V.; Gupta, R. K.; Bhattacharya, S. N. Effect of vinyl acetate content and silicate loading on EVA nanocomposites under shear and extensional flow. Rheol. Acta 2004, 43, 99-108.

11. Prasad, R.; Pasanovic-Zujo, V.; Gupta, R. K.; Cser, F.; Bhattacharya, S. N. Morphology of EVA based nanocomposites under shear and extensional flow. Polym. Eng. Sci. 2004, 44, 1220-1230.

12. Stael, G. C.; Tavares, M. I. B. NMR study of commercial poly(ethylene-co-vinyl acetate). Polym. Testing 1998, 17, 533-541.

13. Chaudhary, D. S.; Prasad, R.; Gupta, R. K.; Bhattacharya, S. N. Clay intercalation and influence on crystallinity of EVA-based clay nanocomposites. Thermochimica Acta 2005, 433, 187-195.

14. Arsac, A.; Carrot, C.; Guillet, J. Rheological characterization of ethylene vinyl acetate copolymers. J. Appl. Polym. Sci. 1999, 74, 2625-2630.

15. Alexandre, M.; Beyer, G.; Henrist, C.; Cloots, R.; Rulmont, A.; Jerome, R.; Dubois, C. Preparation and properties of layered silicate nanocomposites based on ethylene vinyl acetate copolymers. Macromol. Rapid. Commum. 2001, 22, 643-646.

16. Zanetti, M.; Camino, G.; Thomann, R.; Mulhaupt, R. Synthesis and thermal behaviour of layered silicate-EVA nanocomposites Polymer. 2001, 42, 4501-4507.

17. Gupta, R. K.; Pasanovic-Zujo, V.; Bhattacharya, S. N. Shear and extensional rheology of EVA/layered silicate-nanocomposites. J. Non-Newtonian. Fluid Mech. 2005, 128, 116-125. 
18. Chaudhary, D. S.; Prasad, R.; Gupta, R. K.; Bhattacharya, S. N. Morphological influence on mechanical characterization of ethylene-vinyl acetate copolymer-clay nanocomposites. Polym. Eng. Sci. 2005, 45, 889-897.

19. Ramanan, K.; Emmanuel, P. G. Rheology of End-Tethered Polymer Layered Silicate Nanocomposites. Macromolecules. 1997, 30, 4097-4102.

20. Tang, L. W.; Tam, K.C.; Yue, C.Y.; Hu, X.; Lam, Y.C.; Li, L. Influence of the polarity of ethylene-vinyl acetate copolymers on the morphology and mechanical properties of their uncompatibilised blends with polystyrene. Polym. Int. 2002, 50, $325-337$.

21. Wang, Y.; Lopes, F.; Geil, P. H.; Pauda, G. W. Effects of processing on the structure of zein/oleic acid films investigated by X-ray diffraction. Macromol. Biosci. 2005, 5, 1200-1208.

22. Lai, H. M.; Geil, P. H.; Pauda, G. W. X-ray diffraction characterization of the structure of zein-oleic acid films. J. Appl. Polym. Sci. 1999, 71, 1267-1281.

23. Prasad, R.; Gupta, R. K.; Cser, F.; Bhattacharya, S. N. Extensibility of EVA based nanocomposites. J. Polym. Eng. 2005, 25, 305-330.

24. Duquesne, S.; Jama, C.; Le Bras, M.; Delobel, R.; Recourt, P.; Gloaguen, J. M. Elaboration of EVA-nanoclay systems-characterization, thermal behaviour and fire performance. Compos. Sci. Technol. 2003, 63, 1141-1148.

25. Marius, C. C.; David, D. J.; Charles, A. W. Thermal degradation of ethylene-vinyl acetate coplymer nanocomposites. Polymer. 2005, 46, 6947-6958.

26. Zhang, W.; Chen, D.; Zhao, Q.; Fang, Y. Effects of different kinds of clay and different vinyl acetate content on the morphology and properties of EVA/clay nanocomposites. Polymer. 2003, 44, 7953-7961. 
27. Lim, S. T.; Hyun, Y. H.; Choi, H. J. ; Jhon, M. S. Synthetic biodegradable aliphatic polyester/montmorillonite nanocomposites. Chem. Mater. 2002, 14, 1839-1844.

28. Agag, T.; Koga, T.; Takeichi, T. Studies on thermal and mechanical properties of polyimide-clay nancomsposites. Polymer 2001, 42, 3399-3408.

29. Choi, H. J.; Kim, S. K.; Hyun, Y. H.; Jhon, M. S. Preparation and rheological characteristics of solvent-cast poly(ethylene oxide)/montmorillonite nanocomposites. Macromol. Rapid. Commun. 2001, 22, 320-325.

30. Choi, H. J.; Park, S. H.; Yoon, J. S.; Lee, H. S.; Choi, S. J. Rheological study on poly-D(-)(3-hydroxybutyrate) and its blends with poly(ethylene oxide). Polym. Eng. Sci. 1995, 35, 1636-1642.

31. Choi, H. J.; Kim, J.; Jhon, M. S. Viscoelastic characterization of biodegradable poly(3-hydroxybutyrate-co-3-hydroxyvalerate) Polymer. 1999, 40, 4135-4138.

32. Hyun, Y. H.; Lim, S. T.; Choi, H. J.; Jhon, M. S. Rheology of poly(ethylene oxide)/organoclay nanocomposites. Macromolecules 2001, 34, 8084-8093.

33. Zhu, Z. Y.; Dakwa, P.; Tapadia, P.; Whitehouse, R. S.; Wang, S. Q. Rheological characterization of flow and crystallization behavior of microbial synthesized poly(3-hydroxybutyrate-co-4-hydroxybutyrate). Macromolecules 2003, 36, 48914897.

34. Park, S. H.; Lim, S. T.; Shin, T. K.; Choi, H. J.; Jhon, M. S. Viscoelasticity of biodegradable polymer blends of poly(3-hydroxybutyrate) and poly(ethylene oxide). Polymer 2001, 42, 5737-5742.

35. Okamoto, M. Biodegradable polymer/layered silicate nanocomposites: A review. J. 
Ind. Eng. Chem. 2004, 10, 1156-1181.

36. Kim, H. B.; Lee, C. H.; Choi, J. S.; Park, B. J.; Lim, S. T.; Choi, H. J. Preparation and rheological characteristics of poly(epsilon-caprolactone)/organoclay nanocomposites. J. Ind. Eng. Chem. 2005, 11, 769-772.

Figure 1. (a)WAXD peaks of EVA40/clay nanocomposites and pure clay.

(b)SAXS peaks of EVA40/clay nanocomposites.

Figure 2. TEM image of exfoliated EVA40 / clay nanocomposite samples.

Figure 3. SEM micrographs of (a) pure EVA40 and (b) $2.5 \mathrm{wt} \%$, (c) $10 \mathrm{wt} \%$ nanocomposites.

Figure 4. TGA curves of EVA and EVA / clay nanocomposites.

Figure 5. Steady shear viscosity with Carreau model fitting as a function of shear rate at $130^{\circ} \mathrm{C}$ for pure EVA40 and EVA40 / clay nanocomposites.

Figure 6. (a) Storage modulus and (b)loss modulus as a function of angular frequency at $130^{\circ} \mathrm{C}$ for pure EVA40 and EVA40 / clay nanocomposites (c)Plot of storage modulus and loss modulus together.

Figure 7. Stress relaxation test at $130^{\circ} \mathrm{C}$ for pure EVA40 and EVA40/clay nanocomposites. 

Table 1: The processing conditions employed for EVA40 organoclay-polymer system

\begin{tabular}{cc}
\hline Processing Conditions & EVA40 - C30B \\
\hline Residence time, min & 25 \\
Barrel temperature, ${ }^{\circ} \mathrm{C}$ & 110 \\
Screw speed, rpm & 70 \\
\hline
\end{tabular}


Table 2. Zero shear viscosity, relaxation time and power law index of EVA40/clay nanocomposites.

\begin{tabular}{cccc}
\hline Clay contents $(\mathrm{wt} \%)$ & $\begin{array}{c}\text { Zero shear viscosity } \\
\eta_{0}[\text { Pa.s }]\end{array}$ & Power-law index, $\mathrm{n}$ & Relaxation time, $\mathrm{t}$ \\
\hline 0 & 55,760 & 0.62 & 25.4 \\
2.5 & 178,220 & 0.49 & 53.2 \\
5.0 & 402,070 & 0.34 & 68.2 \\
7.5 & $1,421,800$ & 0.25 & 166.0 \\
10 & $4,643,900$ & 0.22 & 430.4 \\
\hline
\end{tabular}


Figure 1.
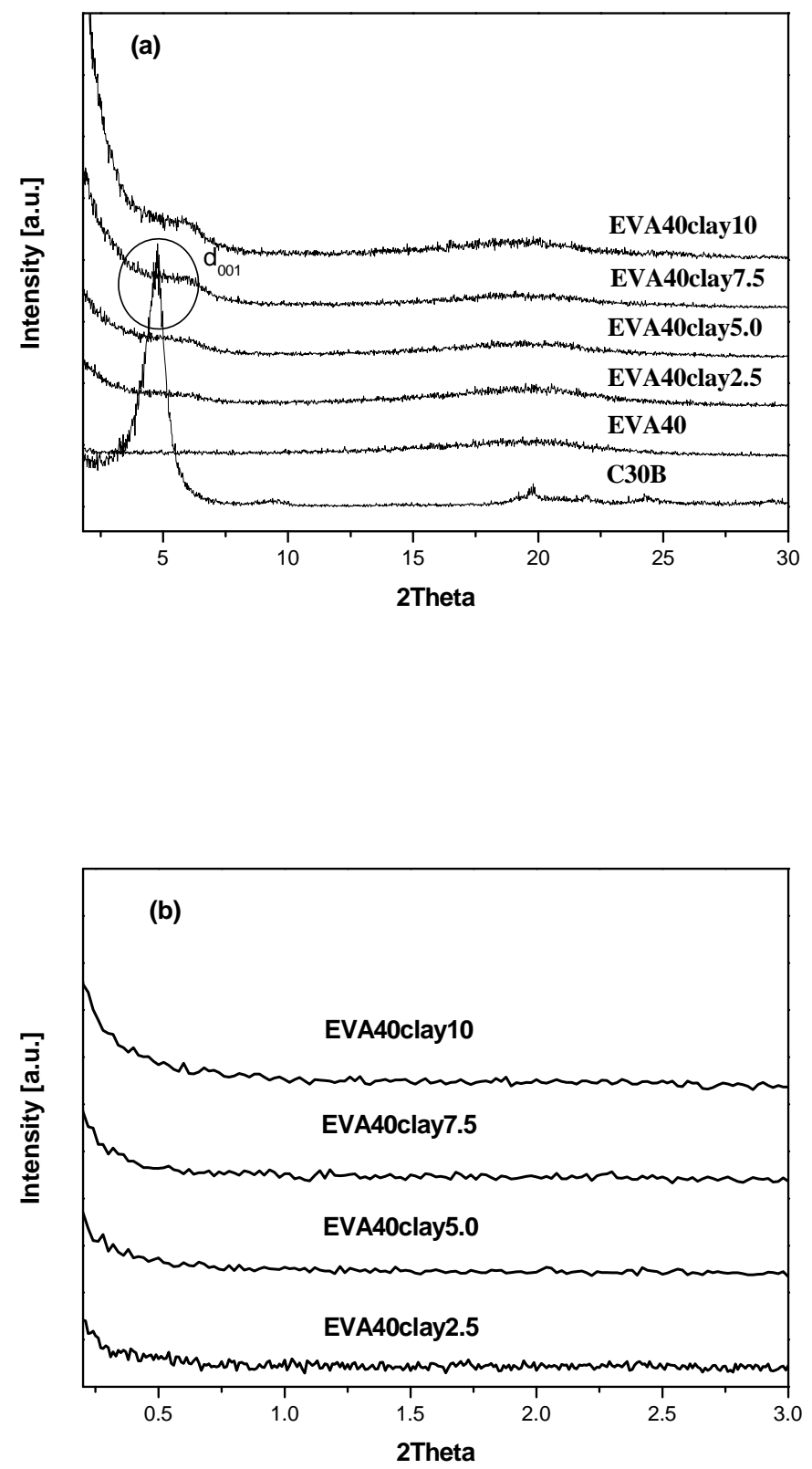
Figure 2.

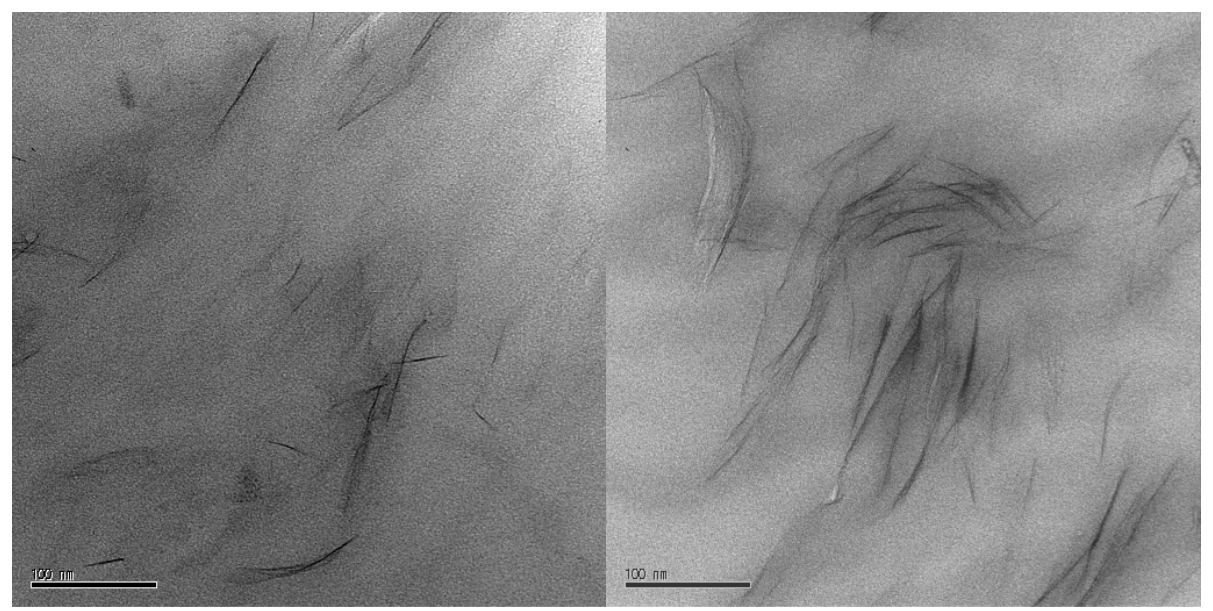

(a) EVA40/clay2.5

(b) EVA40/clay5.0

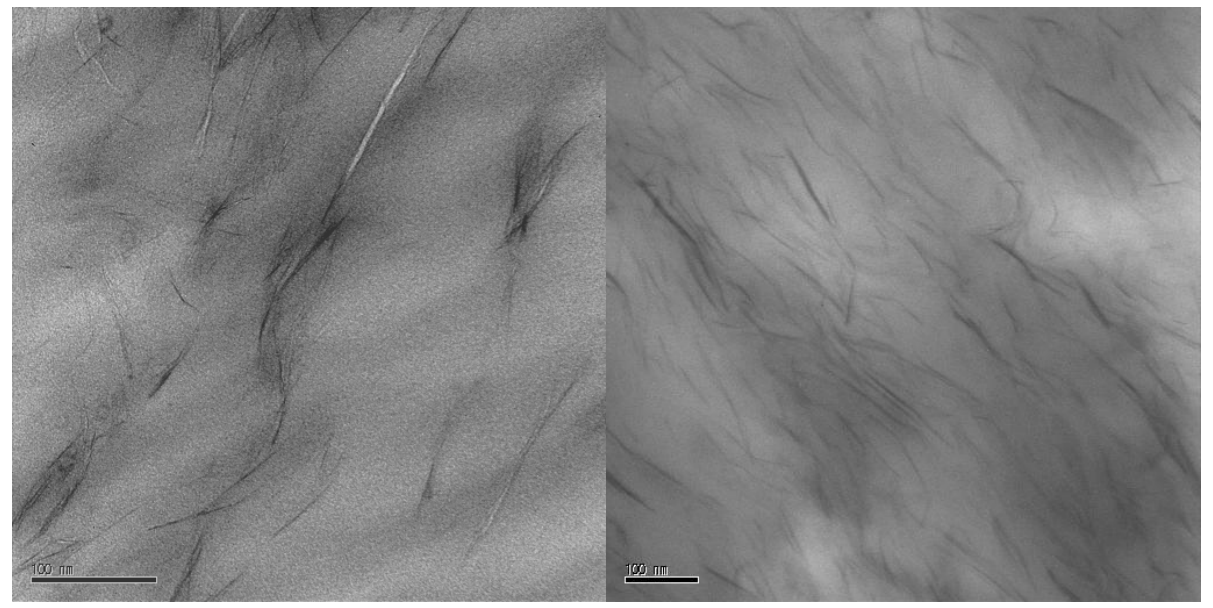

(c) EVA40/clay7.5

(d) EVA40/clay10 
Figure 3.
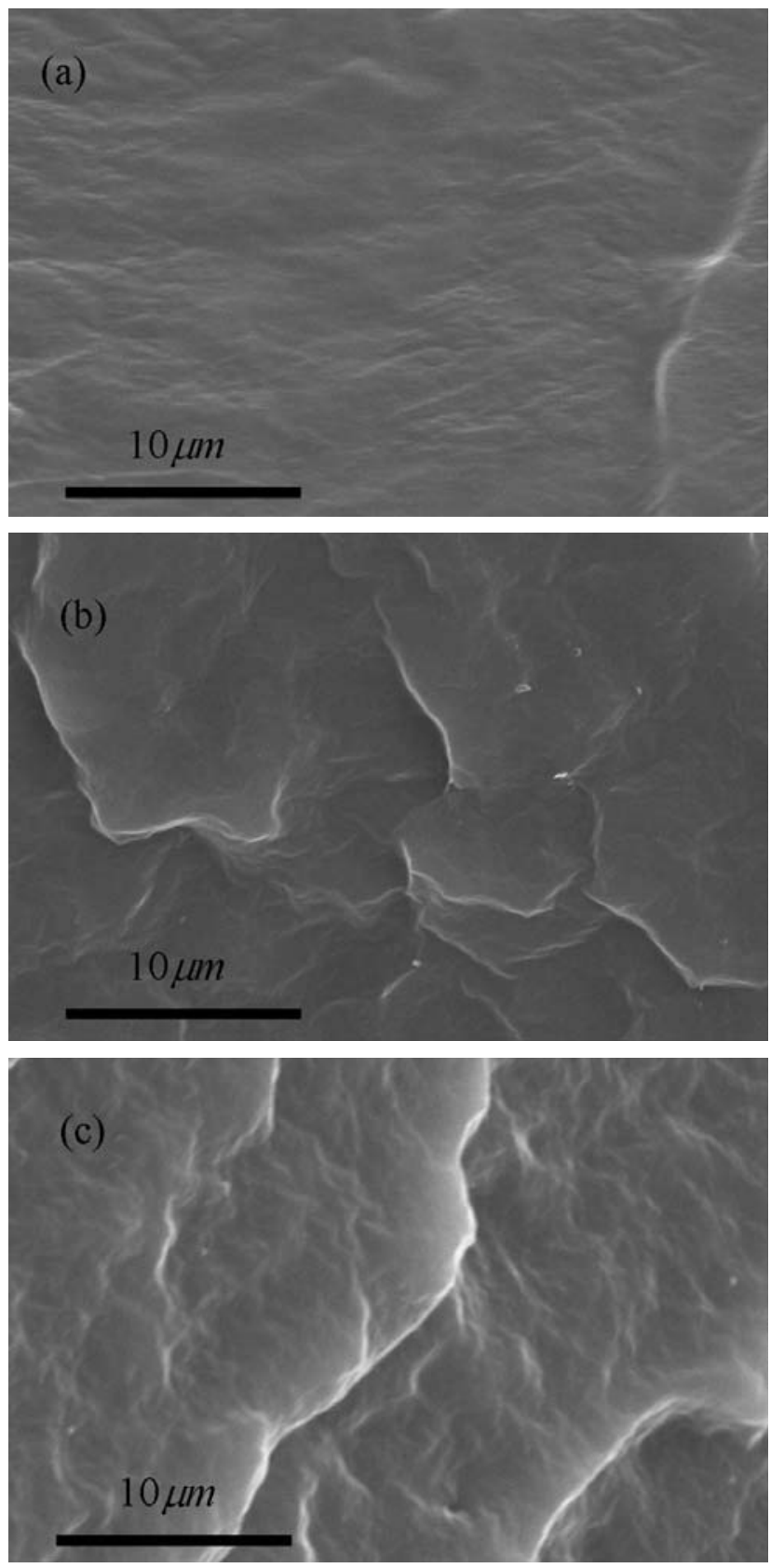
Figure 4.

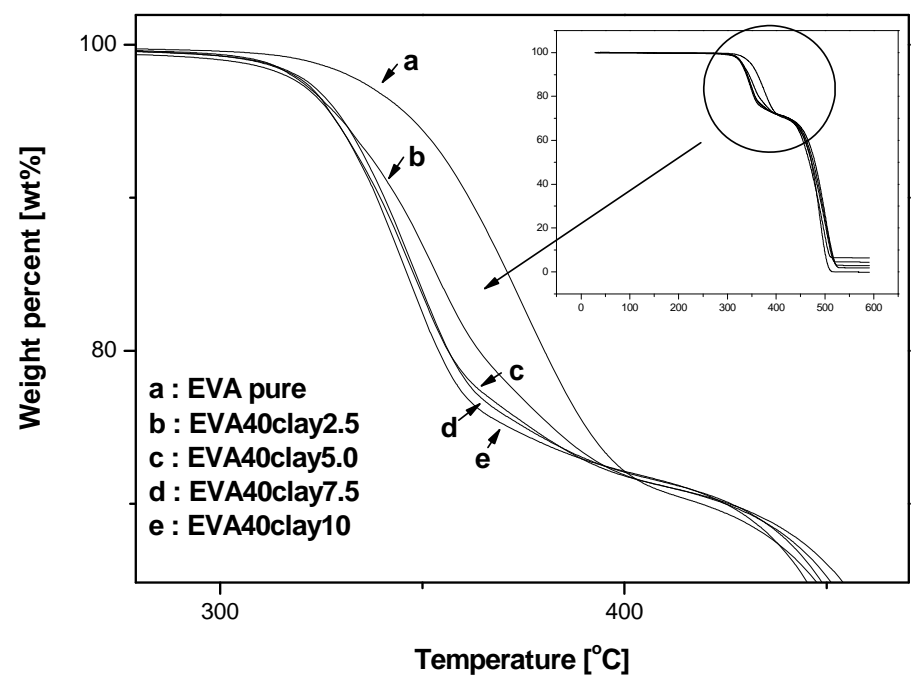


Figure 5.

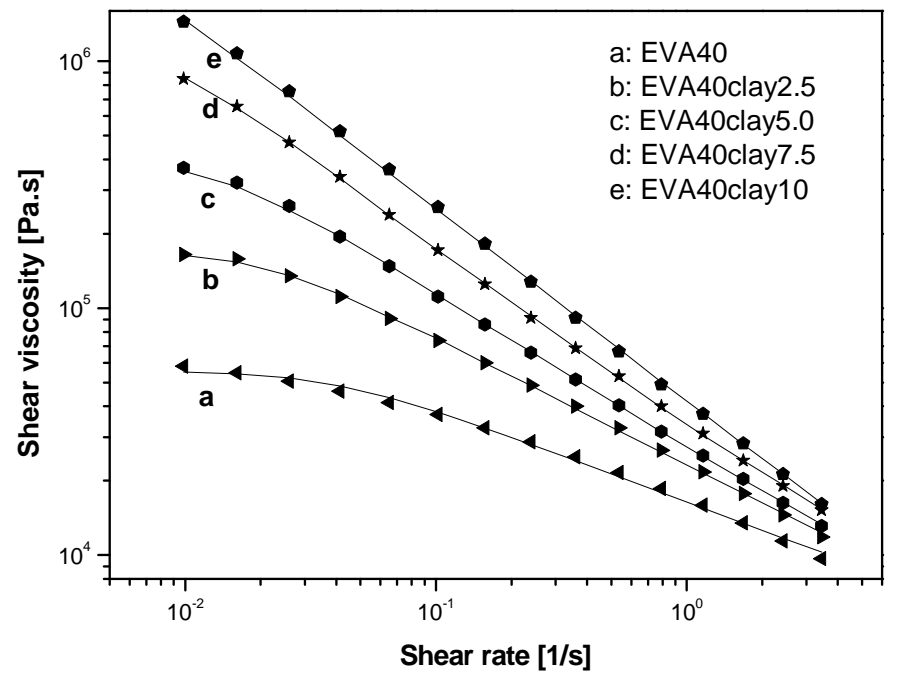


Figure 6.
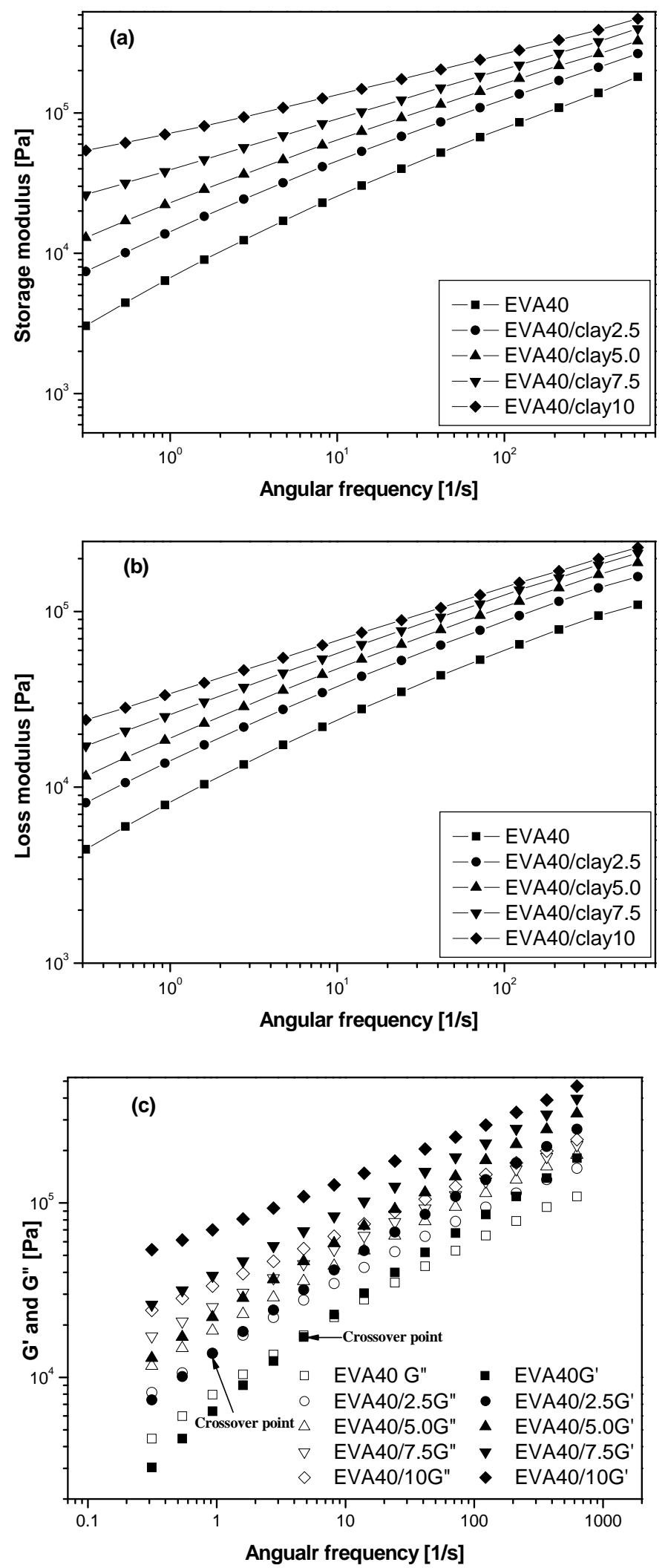
Figure 7.

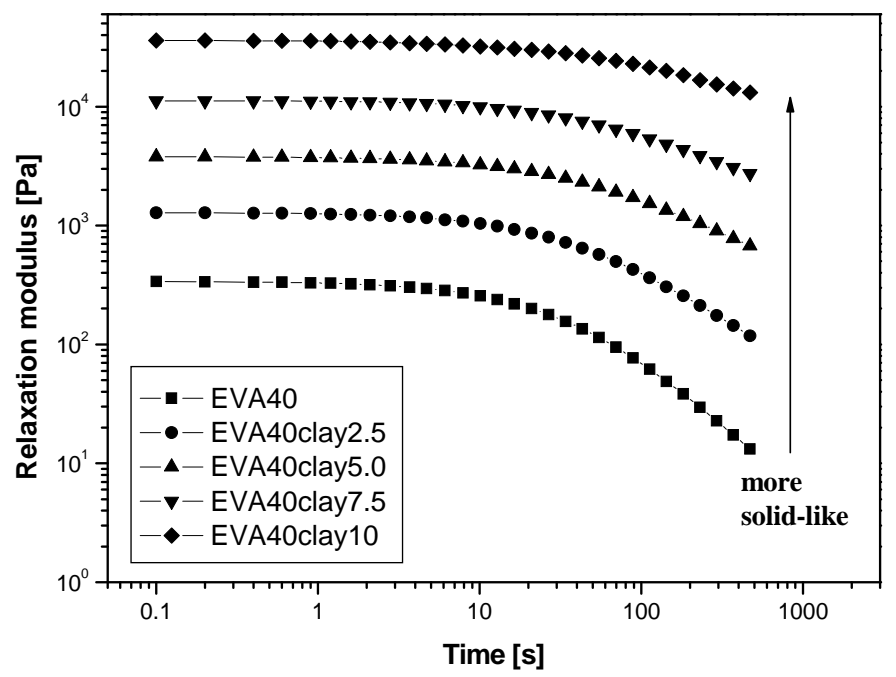

